\title{
Innovation as a lever for sustainable development: the case of agriculture and water management in the region of Sadaguia
}

\author{
Iyad Dhaoui \\ (Research Unit Money, Development and Infrastructure/ Faculty of Economics and Management of Sfax, \\ Tunisia)
}

\begin{abstract}
A central issue around which the recent growth literature has evolved is that of sustainable development. In this perspective, expansions of interest in the analyzing of water resources and the problems to which they are applied should be taken in account. As considered a limiting factor for economic development, water management requires special attention. So, undertaking development of sustainable solutions to 21 st century water resource problems becomes a strategic imperative. But, this is combined with some problems relating to the management of water. This article attempts to further analysis of the role of innovation for a better management of irrigation water. It takes into account all potential forms of technological innovation for sustainable development. This analysis is supporting a questionnaire on irrigation practices targeting fifty farmers in the region of Sadaguia. For this purpose, this paper tries to give some possible reflections that help us to develop the analytical tool that may help us to improving the way towards the amplification of the analysis paradigm.
\end{abstract}

Keywords - sustainable development, water resources, irrigation, innovation, Sadaguia.

\section{Introduction}

In 1987, the Brundtland Report defined sustainable development as "development that meets the needs of the present without compromising the ability of future generations to meet their own needs"1.

This concept is not just about the environment. It is a goal that calls for strategies changes in many sectors and requires coherence between policies.

Everything lies in finding a balance between social, economic and environmental factors that constitute the three pillars of sustainable development. We must therefore take into account the impact of decisions taken at a given time on solutions that provide for future generations.

Sustainable development is a new conception of the public interest, applied to the economic growth and global reconsidered to take into account the environmental and social aspects of a globalized planet. ${ }^{2}$

Sustainability requires the preservation and conservation of global capital over time. The ethical argument is to consider that future generations have the right to inherit (in terms of human and natural capital overall) sufficient capital to enable them to have the measurements and the potential to generate and create a level well-being at least equivalent to that enjoyed by the present generation.

However, natural capital can suffer forms of degradation. To maintain a minimum of 3 rules can be set:

- The use of renewable resources should not exceed the rate of renewal rate;

- Exhaustible resources must be extracted at a rate allowing their replacement by renewable resources;

- Emissions of waste of all kinds should be below the assimilative capacity of the environment.

\section{I.1. Agriculture and Water Management}

In a context marked by the search for food sufficiency and satisfaction of social needs of the population, governments have focused their efforts of operation of more intense the available natural resources and especially, water, farmland, rangelands and fisheries resources.

\section{I.1.1. The role of agriculture in the economy}

Despite the limited resources of land and water, agriculture plays an important role in the economy: it represents a tenth of GDP, exports and investment and employs almost one fifth of the workforce. It is a major source of income for many households in rural areas, which often supplement their income through non-farm activities. During the 10th Plan, the average growth in real terms of production was around 2.6\%, but the overall

\footnotetext{
${ }^{1}$ Two concepts are inherent: the concept of 'needs', in particular the essential needs of the poor, who should be given the highest priority, the idea of limitations imposed by the state of technology and our organization social imposes on the ability of the environment to meet present and future.

${ }^{2}$ http://fr.wikipedia.org.wiki
} 
production has largely kept pace with the growing population and economy. The coverage of all needs for food rose by $65 \%$ between 1987 and 1991 to $78 \%$ between 2002 and 2006.

\section{I.1.2. Water resources in Tunisia}

Water resources are increasingly in demand with the onset of severe phenomena overexploitation of groundwater causing salinisation and degradation of agricultural land particularly in irrigated areas irrigated with water containing salt. Fossil water southern oasis is not spared by this threat. More than $38 \%$ of groundwater is from this non-renewable fossil groundwater

Tunisia, because of its location between the Mediterranean and the Sahara, is an arid country on the majority of its territory. This dryness, combined with the variability of the Mediterranean climate, water is a resource both scarce and unevenly distributed in time and space. The country has about 4250 million m 3 of exploitable resources which 3598 million $\mathrm{m} 3$ considered renewable, for the year 2006, respectively, the equivalent of 420 $\mathrm{m} 3$ and $354 \mathrm{~m} 3$ per capita per year, while usage confused.

Water consumption in Tunisia is characterized by a large agriculture consumes water. In fact, this activity consumes about $82 \%$ of the available potential, followed by drinking water and industrial water, which consume $12 \%$ and $5 \%$, the share of water consumption in the tourism sector remains weak it is of the order of $1 \%$. All socio-economic activities continue to evolve over the next period with increases in the quantities consumed water with the exception of the agricultural sector which is experiencing stagnation or even a decline from 2012. Urban population growth and the consumption of drinking water per capita are real challenges in the arid zone.

If recent performances were impressive, they were accompanied by signs more visible stress on the environment. Between 90 and $95 \%$ of water resources are currently used as running water and overexploitation of surface waters has resulted in lower aquifers and $0.38 \mathrm{~m}$ deep groundwater of $0.74 \mathrm{~m}$. A third of the country's groundwater is highly overused and excessive extraction of groundwater continues despite efforts to regulate and conserve. This exploitation has affected the quality of water and increased salinity. In addition, it has seriously degraded land resources. Nearly 3.5 million hectares of land have been more or less affected by wind and water erosion, and $31 \%$ of arable land is currently seriously eroded. We record each year, a loss of 30,000 hectares of productive land.

\section{II.1. The research context}

\section{Irrigation practices in the region of Sadaguia}

To understand the practices of irrigation by farmers and its impact on sustainable development, we chose a research strategy based on empiricism and hypothetic deductive method. To verify a causal relationship, we have chosen as unit of analysis the Tunisian farmers and specifically those belonging to the region Sadaguia, delegation of Sidi Bouzid West.

The choice of this region as a field of empirical validation is largely justified by its economic dynamism and its privileged position in the Tunisian activity. Indeed, the plain of Sidi Bouzid is devoted to the cultivation of cereals, fruit trees and vegetables. The city is the largest producer of vegetables in the country and one of its main dairy areas. Thus, the exploitation of water reserves would indeed immense.

Fig. 1: Mapping of Sadaguia region

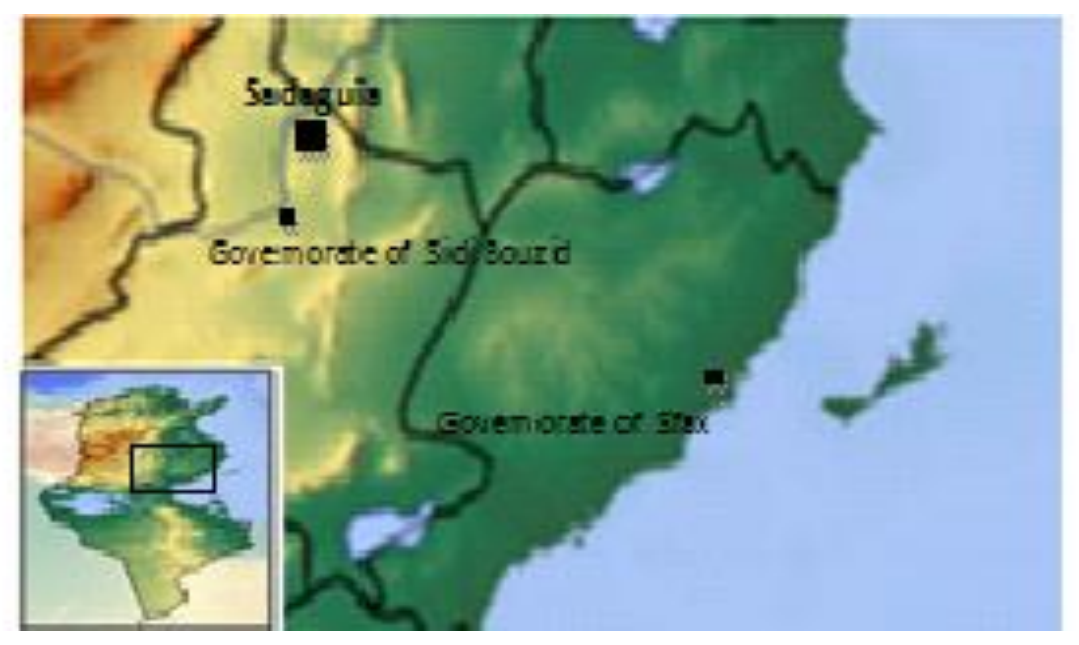

Source: Own elaboration from Google Earth.

II.2. Sampling 
The sample of this research is consistent with the strategy we have adopted to make the decision of individuals (object of study).

\section{II.2.1. The reference population}

Our research question concerns a very specific population such as farmers of the region Sadaguia. These individuals, with different generations, practice irrigated agriculture which relates their income. Their plots are mainly located in areas where there is a more or less significant volume of groundwater.

\section{II.2.2. The sample size}

Determine the sample size is tantamount to estimate the minimum size needed to obtain results with a degree of confidence. ${ }^{3}$ Our sample is consisted of 50 individuals (farmers) who have adopted irrigation as agricultural technique.

\section{II.2.3. The method of data collection}

This work is based on responses from 50 people (men) questioned in situ, i.e. at their place of work (mostly fields) or at home. Sampling was done randomly but all use irrigation for at least a year.

Moreover, for a study explanatory, the ideal is to examine all the elements that constitute the population concerned. We tried to select a fraction to be the most representative of the reference population. ${ }^{4}$

Besides explanatory intends of this research, the significant number of farmers interviewed justifies our use of a question nnaire survey. We tried to get the richest and the most objective possible information, limiting the risks of reciprocal influence between the interviewer and the interviewee.

\section{Tools and technical data analysis}

In this section we have tried to collect the information collected and then to treat them so that they are put into a form that can provide answers to various questions. Thus, we created a database with the "Excel" software. Then, all information is stored and analyzed in the software specially designed for this purpose.

\section{IV.1. General Characteristics of the sample}

\section{The results}

The 50 individuals were selected at random. All individuals in our sample practice irrigation, as private or main activity or as sideline. We present below the different characteristics of our sample.

Table 1. General characteristics of the sample $(N=50)$

\begin{tabular}{c|cccc}
\hline & Mean & Median & Min & Max \\
\cline { 2 - 5 } Age (years) & 48.26 & 52.50 & 21 & 58 \\
Area & 1.86 & 2.00 & 1 & 3 \\
Number of land & 1.38 & 1.00 & 1 & 3 \\
Year (s) of practice irrigation & 25.16 & 30.00 & 1 & 35 \\
\cline { 2 - 6 } Source: Own elaboration from SPSS.
\end{tabular}

As shown in the table above, the average age of respondents was 48.26 years, with a minimum of 21 years and a maximum of 58 years. The calculation of the median informs us that half of individuals (25 of 50) have more 52.50 years. Individuals in our sample are mainly farmers (72\%). However, we noticed that $24 \%$ of respondents are workers.

Therefore, these individuals use irrigation as an activity which can provide needs for the family, onsite or remote, or as the creation of ancillary revenues. $4 \%$ in our sample are active or retired employees, who settled in the region to invest in agriculture mainly against season. For the analysis of our field we have a total of $28 \%$ of individuals who are not rural farmers but still practicing irrigation as a sideline, either themselves or assisted labor.

On the number of years of practice as a technique of irrigation for agricultural production, all practice irrigation for at least one year, with an average year of practice located at 25.16 years and a median of 30 , this means that half of the individuals are using to practice irrigation for 30 years at least.

\footnotetext{
${ }^{3}$ Note that the sampling rate, that is to say the ratio of the sample size $\mathrm{n}$ in the population size $\mathrm{N}$, practically does not intervene in the calculated accuracy of results, except if it exceeds a limit set empirically often 10\% (n / N 1/10) (Evrard et al, 2003).

${ }^{4}$ If we questioned a limited number of people, we get a reasonably accurate estimate of the behavior of the entire population (Evrard et al, 2003).
} 
Used plot size varies; it is from one hectare to 3 hectares for the largest, with a mean of 1.86 hectares. The median indicates that half of the individuals cultivate a parcel of at least 2 hectares. We can therefore noted that the size of land used for irrigation in the region Sadaguia is random, but does not vary significantly from farmer to another. This factor is dependent on the one hand on the financial means of the operator (financial capacity for investment development) and secondly, the mode of acquisition of land (purchases land are often larger in area than the inheritance family land). But essentially, this factor is explained by constraints on water sources that are not so abundant in this region. In addition, rural farmers representative of our sample have a land in average of 1.38. More than half of individuals have at least 1.38 and maximum land plots owned by a farmer is located 3. This does not mean that it is impossible in this region have more than 3 lands, but in our sample it is. However, growing in small plots may cause higher consumption of water as this can complicate operations related to irrigation. Also, trying to irrigate tired and unstructured land requires more water. Similarly, at the time of planting or sowing, it is preferable that the soil is loose and airy. This allows the plant roots to grow easily and allows savings of water.

\section{IV.2. Statistics on the irrigation area}

Fig. 2: Area suitable for irrigation

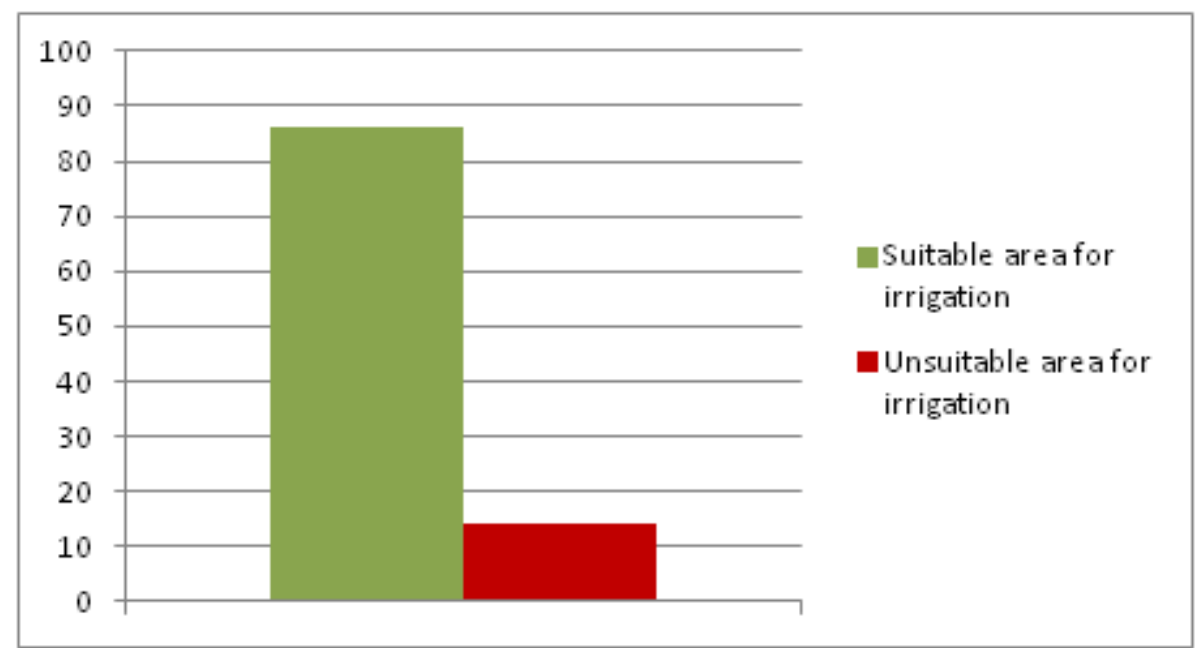

Source: Own elaboration from SPSS.

We found that nearly $86 \%$ of farmers (43 individuals) operating in areas suitable for irrigation. However, there remains a significant proportion (14\%) who invests in areas not favorable to the operation of irrigation. We note that the choice of a suitable area for irrigation has many advantages in terms of water consumption. In fact, before any installation work of an irrigation system, it is essential to ensure the availability of the resource over time. Sometimes it is more interesting to not irrigate in terms of investment costs and operating of such device. Similarly, the soil and climate of the micro-region are decisive in the choice of irrigation. Moreover, the rotation can lead to change the irrigation system over the years. These changes must be provided before the establishment of the irrigation network ${ }^{5}$.

In a sample of 50 individuals, there were 49 individuals $(98 \%)$ who do not have a statement or a debit authorization waters although they operate in areas suitable for irrigation. But it should be noted that these regulatory documents provide a framework for levies on land to prevent water scarcity and sharing sustainably and equitably this resource.

\section{IV.3. Statistics on equipment and maintenance}

Fig. 3: Some statistics of equipment and maintenance

\footnotetext{
${ }^{5}$ Irrigation network is a network of permanent and temporary conduits (canals and pipes) that supply water to irrigated lands from an irrigation source.
} 


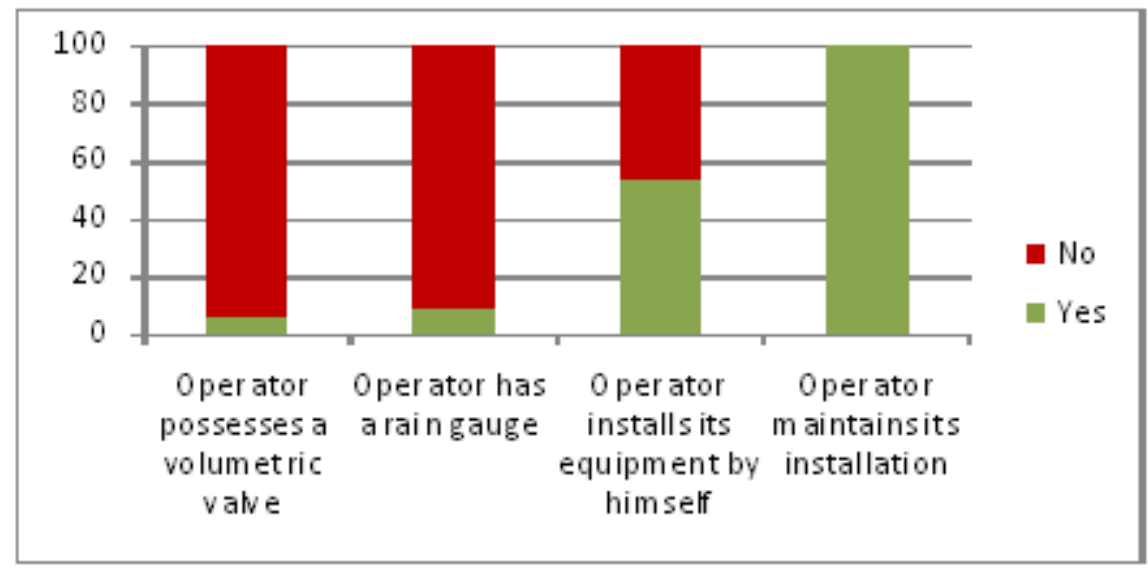

Source: Own elaboration from SPSS.

Volumetric valve or other means to quantify the sampling is essential to help manage water resources and organize levies on the scale of a watershed. According to the previous figure, it was found that only $6 \%$ of farmers have a volumetric valve. The farmer must have a device (system and programming) correctly installed and functional. He must also know the amount of rainfall on or near its operations. To do this, he must have at least one rain gauge.

Otherwise, the majority of farmers do not have a rain gauge (on a sample of 50 farmers, we identified only four who have ones). The rest rely on mental calculations on the needs of the plants in the fall of rain.

Moreover, we can distinguish two categories of equipment for irrigation: those used to bring water from available sources (rivers, lakes or dams, groundwater) and those used for the irrigation itself (that is to say to deliver water to the plants).

In the first category, we find: drilling, pumps, irrigation schemes, canals, waterwheels. In the second: sprinklers, guns, sprinklers propelled drippers. In our study, nearly $54 \%$ of operators install their irrigation equipment by themselves. Failure of a specialist in the field can cause water losses because the emergency equipments are not installed or installed in an inappropriate manner, this sometimes complicated equipment maintenance. Thus, we must take into account water losses along the pathway, and if necessary arrange a small margin of safety in case of accident.

In addition, we should consider the slope (capital factor of irrigation), which determines the velocity of the water surface. Plots to uniform slope and low amplitude are well suited to irrigation because they reduce costly excavation. Apart from specific topographical conditions etc.., the pipes channels are running freely, without being affected by inequality topographical and soil; and water losses and the amount of water is relatively low.

The cost of work is relatively high because PVC pipes ${ }^{6}$ are used, and if the work is done correctly, certain durability can be expected. It is desirable that the maximum speed of the water flowing in the channels in the pipe is lower than the speed of $3 \mathrm{~m} / \mathrm{s}$; in the case of concrete channels, $5 \mathrm{~m} / \mathrm{s}$. PVC Channels prevent damage due to friction of the material of the pipes. The minimum speed should be greater than $0.3 \mathrm{~m} / \mathrm{s}$. to prevent the accumulation of soil / sand suspended in the pipe. When sending turbid water containing much soil / sand in suspension, a speed greater than $0.6 \mathrm{~m} / \mathrm{s}$ is desirable. An approximation of the pipe section is made from the pump flow applied, and given the speed range above design, the pipe diameter is set by holding the overall availability of materials and their prices, ease of maintenance etc.

Overall, the maintenance of the installation can prevent certain fungal diseases and can raise the appearance of water leakage. An irrigation system must be maintained, repaired over time. To remain effective, each piece must be replaced by a piece of identical characteristics. It is therefore important to keep all the technical information.

\section{IV.4. Irrigation methods}

\section{IV.4.1. Runoff irrigation: a traditional method of irrigation}

Runoff irrigation is to supply water to the highest point of the land and let it flow by gravity. The water is then distributed to the field or flood (basin irrigation) or in furrows in the ground (furrow irrigation) or by

\footnotetext{
${ }^{6}$ Polyvinyl chloride (PVC) pipe is made from a plastic and vinyl combination material. The pipes are durable, hard to damage, and long lasting.
} 
surface runoff boards watering (irrigation boards). However, this method causes a significant loss of area due to the large number of partitions.

Fig.4: Percentage of irrigation methods

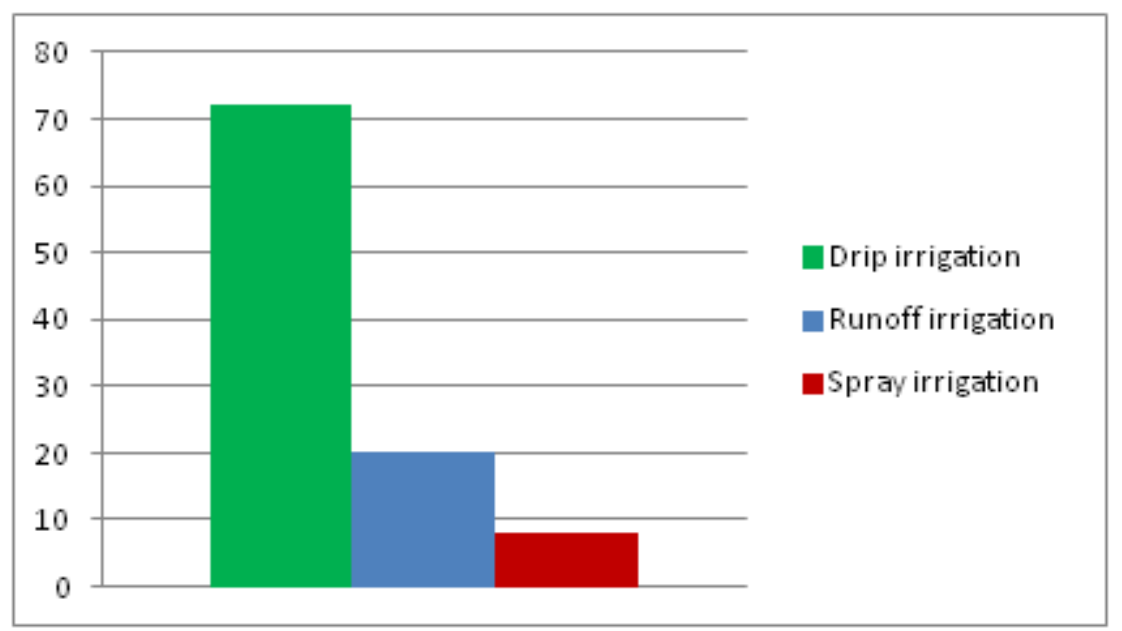

Source: Own elaboration.

In our sample, nearly $20 \%$ of the farmers use this method, a significant proportion still use this method, which is expensive in terms of water consumption. Mismanagement of water is noticed in the case of impounding a pond with a stream of water at low flow. As a result, the time of impoundment basin is too long. The upper basin adjacent the feed channel will receive an excessive amount of water because of the water test for too long. By cons, the other end of the pool receive an insufficient amount of water will remain dry and plantations in this end will wither for lack of water.

\section{IV.4.2. The spray irrigation}

The technique of sprinkler is modeled on the natural rainfall. The water is forced under pressure in a pipe system, then it is scattered by the rotary sprinkler in the form of artificial rain.

To better conserve the amount of water, sprinkler irrigation is recommended in the following cases:

- Shallow-Soils cannot be properly leveled by surface irrigation;

- Permeable soils do not allow a uniform distribution of water in the context of irrigation runoff.

By cons, this method of watering is discarded in regularly windy areas (winds greater than 4 or $5 \mathrm{~m} / \mathrm{s}$ significantly degrades the homogeneity of the spray) and also when irrigation is done with salt water on the foliage of plants sensitive to salt.

In a set of 50 farmers, we identified only four practicing this method. Indeed, this method is designed primarily for field crops and is not suitable for growing vegetables, main activity in Sadaguia area.

\section{IV.4.3. The drip irrigation: a method of modern irrigation}

The drip irrigation is to bring the water pressure in a pipe system, generally PVC, and this water is then distributed to the field drops by a large number of emitters distributed along rows plantations. In drip irrigation, water is delivered to the plant at low dose, lead to a wetting of fraction of the soil. This allows limiting losses by evaporation and percolation. It also helps reduce weed growth. Therefore, the choice of irrigation system will determine his driving. A drip system is more efficient, but under certain conditions, the spray may be recommended. Note that this analysis is a static approach since we made observations in a given time.

This method is illustrated in the figure below:

Fig.5: The drip irrigation network 


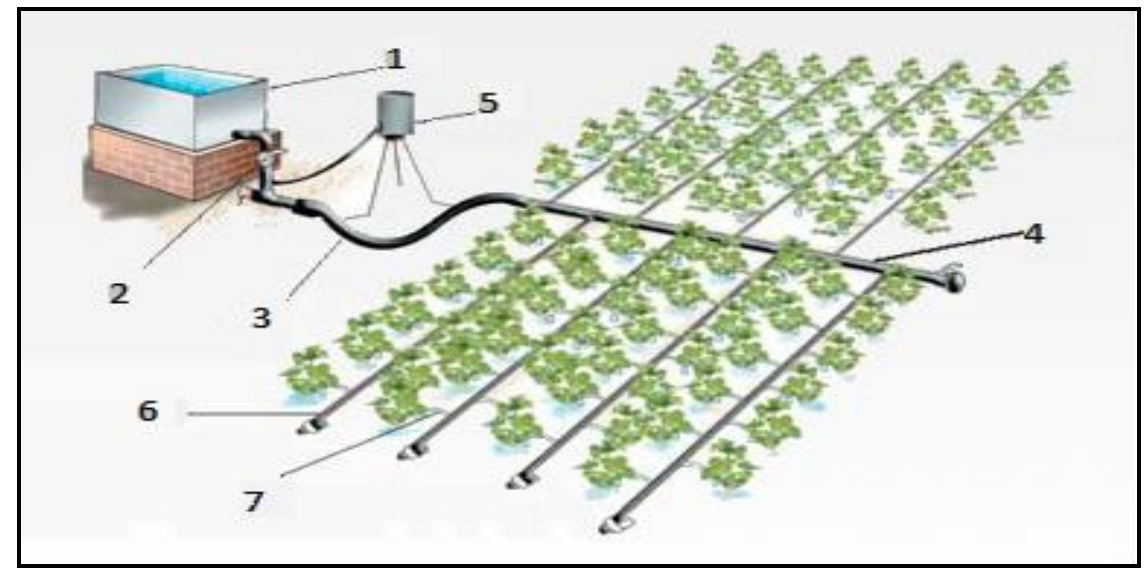

Legend: 1 - water tank 2 - control valve 3 - main line 4 - secondary line (ramp door) 5 - filter 6 - lateral line (ramp) 7 - micro-tubes (drippers)

Source : Application et adaptabilité des technologies de la micro irrigation développées par iDE aux contextes climatiques et pratiques burkinabés, www.fondationensemble.org

The majority of farmers (72\%) are engaged in drip irrigation as shown by the results of the questionnaire. To know the impact of the introduction of this method on water consumption in a dynamic perspective that spans several years, we compared the depth of wells with the utilization of this method for the early 1960 (date of operation of the first well) to today.

Fig.6: Comparison between the depth of wells and drip irrigation

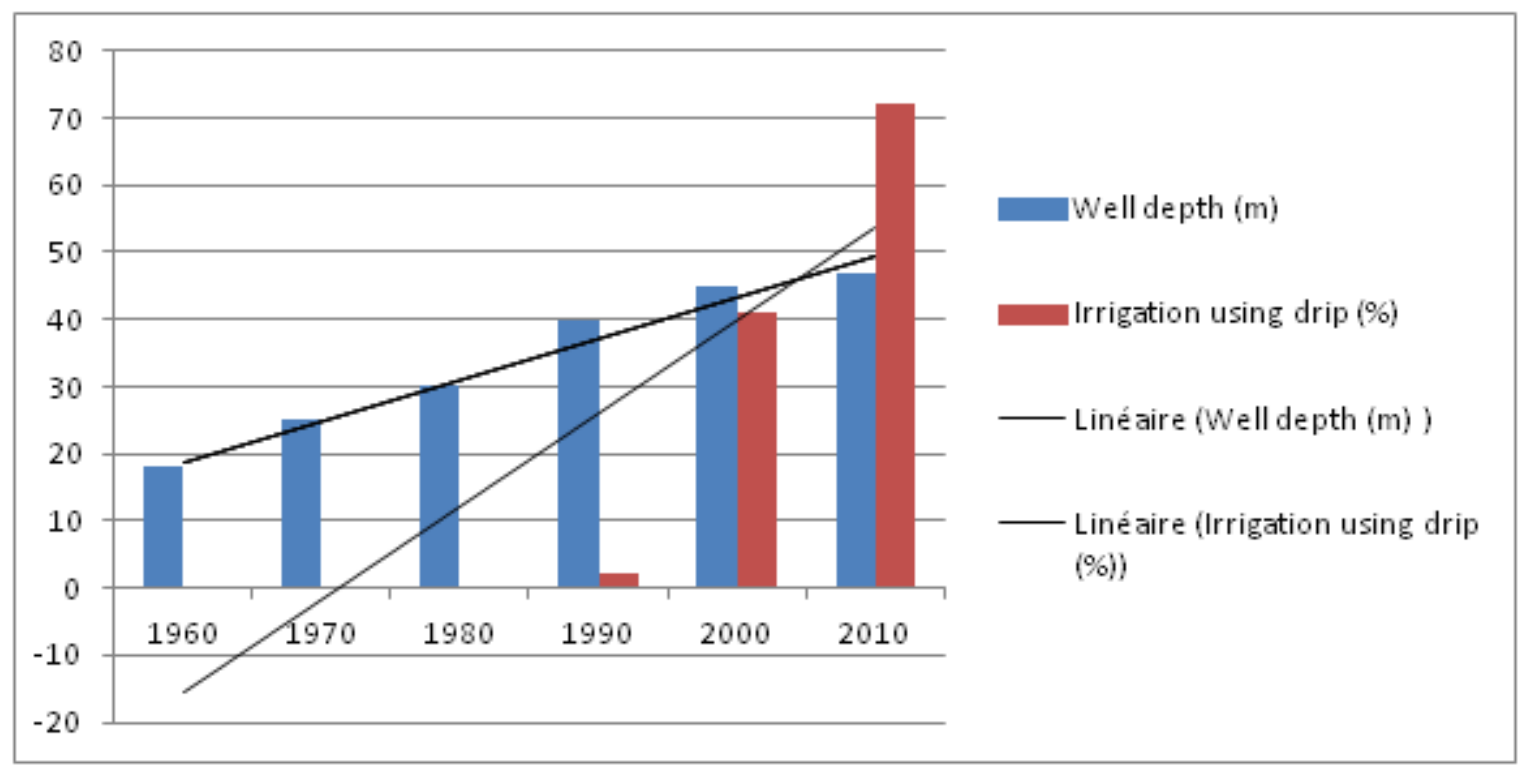

Source: Own elaboration from SPSS.

An overview shows that the introduction of the method of drip irrigation has fade away and fade the deep wells. Since the 1960s and until the late 1980s, the well depth pass from $18 \mathrm{~m}$ to about $40 \mathrm{~m}$, that is to say, the depth is doubled in only 30 years. Note that this period corresponds to a complete lack of method of drip irrigation. But in the early 1990s and especially the early 2000s, we note that a decrease from 40 to $47 \mathrm{~m}$ in 2010 , an increase of only $7 \mathrm{~m}$ depth over a period of 30 years ( 5 and only $2 \mathrm{~m}$ successively for each decade), and despite a relative increase in irrigated areas. This period coincides with a growing use of drip irrigation especially in the early $2000 \mathrm{~s}$.

To conclude, we can say that the introduction of modern irrigation methods, namely, the drip irrigation has several advantages in terms of saving the amount of water in a sustainable development that aims to protection of groundwater.

\section{IV.5. On what basis the farmer determine the amount of irrigation water}


During irrigation, the operator takes into account several elements he sees necessary.

Fig.7: The quantities of water irrigation foundation upon

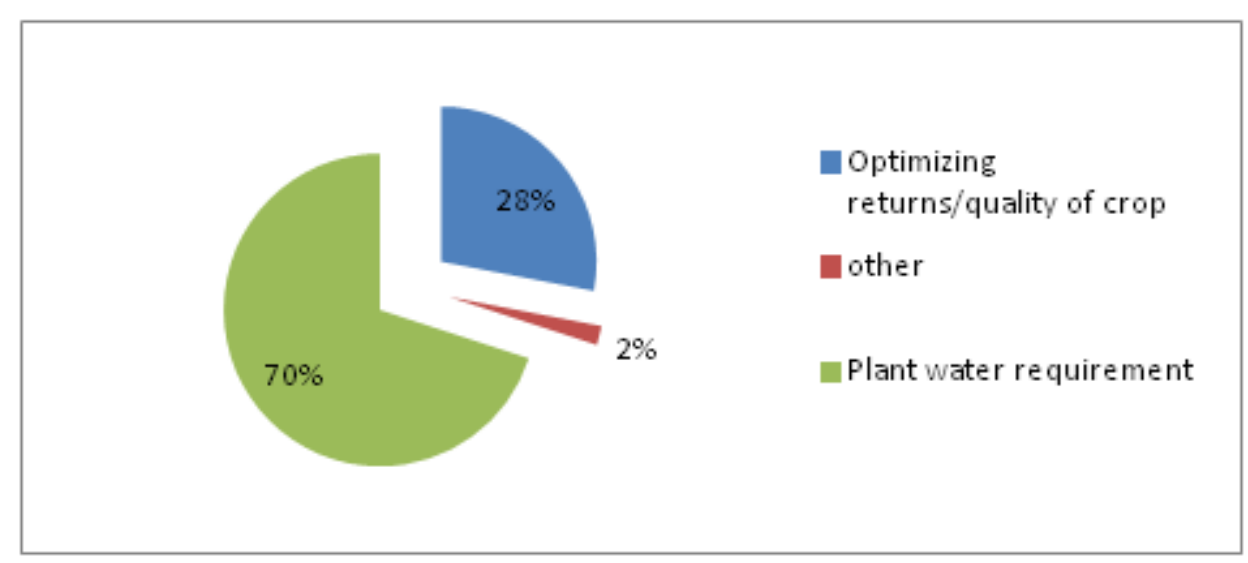

Source: own elaboration from SPSS.

According to the previous figure, we see that the consideration of the water needs of the plant during irrigation is high ( $70 \%$ of farmers take this into consideration). We also noticed that for $28 \%$ of the farmers (14 out of 50), this amount of water is determined on the basis of optimizing the performance or quality of the crop. Thus, these two factors are key determinants for the amounts of water for $98 \%$ of farmers.

But cultures influence the mode of irrigation, by nature that does not ally with all systems; or by their water needs which can change the rotation of watering. Consequently, the amount of water varies with climate and species and the degree of evolution of the vegetation. Changes due to climatic factors are essentially variable from one year to the other after the regime of temperature, rainfall, wind, humidity, etc.

In addition, we must choose the irrigation time. Indeed, the dominant physical quality of the plant is its temperature. The optimum temperature may be about $25^{\circ}$ for the majority of plants during the active season of vegetation. A supply of very dry water on the land can lead to the phenomena of hydration which may dangerously raise the soil temperature. This is why we recommend not watering in the heat. Similarly, excessive irrigation causes runoff and drainage. These waters are loaded with nutrients and pesticides, and soil, reach gullies and streams and cause: pollution of drinking water, eutrophication of rivers and increased aquatic species mortality. Thus, the farmer must know the consequences of excessive irrigation.

Some operators give weather conditions, especially rainfall, a great importance in the conduct of its irrigation. But other operators consider them with futility.

It should be well noted that rainfall is an essential parameter in irrigation. Rainwater, when properly taken into account, saving money and avoiding phenomena of drainage and runoff by irrigation on soil already saturated with water.

So, and in view of the observations made above, additional efforts should be considered to better inform farmers. Effective information contributes to the training of farmers in good agricultural practices and allows preserving the maximum amount of water.

\section{Recommendations}

In order to boost innovation policy in the agriculture sector in Tunisia, an essential factor for the protection of water resources and for a sustainable development, we propose the following policy recommendations:

\section{V.1. Develop methods of access to water resources}

Droughts and desertification are major obstacles to food security. Farmers in drought-prone regions are faced with more frequent dry periods by the onset of climate change ${ }^{7}$.It is expected that by 2030 , the effects of climate change, coupled with unsustainable use and unevenly distributed water around the world, some 3.9 billion people live in areas with water shortages ${ }^{8}$. Similarly, climate change causes changes more harmful that can ruin crops and farmland to inflict extensive damage in the long term.

Therefore, the developed policy must give primacy to water safe and reliable so that agricultural production is sufficient to ensure food security. This is justified by the fact that cultivation is impossible if water

\footnotetext{
${ }^{7}$ In Africa, 75 to 200 million people could be affected by new water shortages by 2020 .

${ }^{8}$ OCDE, 2010
} 
is not available in sufficient quantity and at the right time. Also, effective political action to address climate change and mitigate its effects is a prerequisite. Moreover, it is necessary to increase investments on agricultural research in the field of water crisis and generate solutions in the form of protective infrastructure and agricultural tools helping to limit and adapt to the conditions of chronic lack water. Finally, coordinated and granted policies worldwide are required to attempt to resolve the uneven distribution of water resources and ensure that farmers, especially in drought-prone areas, access to a supply of clean and reliable water.

\section{V.2. Encouraging innovation}

Innovation plays a key role in preserving the amounts of irrigation water. Thus, it would be good that developed policy is based on scientific information and facilitates continuous innovation and development of technologies to improve the rational use of water and agricultural knowledge.

For example, The phytopharmaceuticals ${ }^{9}$ play an important role in water conservation because they effectively control invasive alien species that threaten scarce water resources. Reducing the struggle between crops and weeds to appropriate moisture, herbicides can also help improve performance without additional water. In addition, special biotechnology allowing plants to cope with drought and other situations of water stress, such as floods or high salinity, presents a serious potential for more efficient use of water. The potential of biotechnology goes beyond food production - its applications in wastewater treatment and soil remediation should also be studied. Research and innovation in sustainable agricultural practices, enforcement mechanisms of plant protection products more effective, treatment facilities and water supply, as well as practices of rational use of water in all sectors, can really make a difference in the ability of farmers to grow sustainably challenges under water scarcity.

The State shall undertake to provide farmers with the technology they need to maximize the efficiency and rational use of water, while recognizing that effective fight against the lack of water involves measures of from all participants.

Similarly, the water sector requires innovative use of financial instruments and investment strengthens the integrated management of water resources at the local, regional and restores natural capital.

Also, we note the important fact before any questioning the choice of network hardware, to fully understand the characteristics of the water delivered (in whatever medium and owner) available flow, pressure, temperature, chemical nature, amount of suspended matter, etc.. Indeed, some of these features induce the specific hardware. In this perspective, several technologies and management techniques offer interesting possibilities, such as networks of automated sensors soil moisture and micro-irrigation. But technological developments are not without risks. Some modern irrigation techniques that conserve water and increase crop returns may increase the risk of flooding and soil erosion. To adopt, for example, micro-irrigation technologies by farmers for improved water efficiency, resource increasingly rare: Technology is a system of drip irrigation with micro-tubes that replace drippers used in conventional systems. The system is available in different sizes and can meet the needs of farmers under the surface and they have this at lower prices than other techniques currently on the market. It also allows a reduction in water consumption by $50 \%$ compared to traditional irrigation methods. The system is suited to all types of crops and can be done even on land or slope does not allow the installation of traditional irrigation methods.

\section{V.3. Sustainable management of water}

Policy for the sustainable management of water must enable and promote farming methods most constant and most effective to optimize the use of water in agriculture.

Some concrete steps can be taken now to use water more efficiently in culture. Among these include repairing leaks along pipelines and conduits; improvement or modernization of irrigation systems, promoting the development of vegetation cover to reduce evaporation of soil water. Awareness of farmers on the proper use of plant protection products also helps to reduce water consumption. Beyond the management practices of water resources, improved agricultural performance helps reduce water consumption. An optimization of production per hectare of crop allows farmers to produce more food without increasing its footprint in water ${ }^{10}$.

To improve productivity levels, we need a more effective dissemination of agricultural knowledge and ensure farmers' access to agricultural raw materials such as quality seeds and crop protection products to reduce preand post-harvest losses due to pests and diseases. Climate (temperature, wind, humidity, sunshine) is causing a potential water demand. ${ }^{11}$ In addition, farmers can reduce their water consumption by adopting certain techniques and making the right choice:

- Select crops according to their water consumption and climate: focus on crops that need less water;

\footnotetext{
${ }^{9}$ They are a complex mixture derived from plant sources that is used as a medicine or drug: they are preparations to protect plants and cultured products. They are among the pesticides, which also include biocides and pesticides designed to human and veterinary use.

${ }^{10}$ In many parts of the world, cultures produce only $20 \%$ of the performance achieved in developed countries.

${ }^{11}$ The phenomenon called Potential Evapotranspiration (PET).
} 
- Collect rainwater;

- Bundle irrigation: Establish a system of collective irrigation;

- Choosing the right material to reduce water losses;

- Start irrigation when necessary; take into account the water content of soil and climatic conditions;

- Get a better distribution of water, not water to the plot, not the roads around;

- Check the equipment to detect leaks and repair them automatically.

In this context, the rational management of harvest, store and process, acquires a considerable economic and environmental importance and requires a long-term strategy involving large investments and maintenance programs that affect the real cost of water.

Tunisia has given priority over the last 25 years to exploit water resources in executing plans drawn for the three geographic regions. The agricultural development strategy focused primarily on the mobilization and efficient use of water resources. Policy of sustainable development should also address the impact of urbanization on water supply and ensure that the increased demand for water for domestic and industrial does not happen at the expense of agriculture. The use of treated wastewater for irrigation in agriculture is one of the measures to be significant potential. Conservation, desalination, recycling and rationalization of agriculture must be part of the measures to be taken to ensure sustainable use of water in the medium and long term.

By any reasonable scenario, the availability of water will limit the future growth of the agricultural sector. The measures must be taken to conserve and increase the efficiency of water use. On a technical level, effective management of water resources requires a strict control of losses by implementing good pumping systems and efficient distribution networks. But the complex structure of land tenure, absenteeism, credit systems in agriculture, combined with the lack of extension services makes it more problematic for significant increase irrigation efficiency in the foreseeable future. Therefore, the management of water in agriculture is becoming one of the major challenges for collective achieve sustainable development of the whole earth and preservation of this vital resource.

\section{V.4. Dissemination of technologies and knowledge}

The sustainable development policy should facilitate farmers' access to training in farming methods while ensuring optimal technology and infrastructure necessary for their implementation are available. So, it would be good that farmers can make use of existing tools and practices for the efficient use of water, but in rural areas access is often limited.

Collaborations across sectors and within the chain of agriculture can contribute to that technology and knowledge useful to actually reach those who need it most. In this perspective, we should encourage partnerships between the public and private sectors because they can effectively share knowledge and facilitate access to inputs. Various partnerships may actually facilitate the distribution of agricultural inputs, such as seeds and plant protection products, the implementation of agricultural infrastructure, such as irrigation systems and the construction of transport links ensuring water accessibility to the most remote areas. Training programs provide farmers with relevant knowledge on local plan essential to apply the techniques most rational in water management, optimize the levels of agricultural productivity and farming methods more sustainable.

It is vital to continue research into sustainable farming techniques, agricultural advice and effective outreach campaigns, providing farmers with training in advanced techniques of optimal use of water in the cultures. The policy should encourage farmers to follow sustainable farming practices to maximize the skills of agriculture to conserve natural resources.

Thus, a transformation in the culture of water is essential. This change will affect all those involved in the management of water, namely planners, executive officers as well as the different users. It will interest all features that organize water management hat is to say the technical, legal, institutional, economic, social, cultural and ecological aspects.

\section{Conclusion}

Put technological innovation for sustainable development is a complex challenge, because the concepts of innovation and sustainable development are both multidimensional. Also characterize the technologies for sustainable development, knowing that the characterization should not focus only on the technology itself, but also on the process of design and delivery. The key to sustainable development lies in the following three: technology, organizational innovation, changes in lifestyles.

In addition, the Tunisian natural environment is fragile and the natural resources are limited. The agriculture sector, a major consumer of water, is one of the main drivers of development. The debate on the governance of water is always present. Research and development is a serious improvement potential for the future of agriculture. Saving water is a vital issue of sustainable development. So, agricultures shouldn't deplete water resources. In our study on water in irrigation area Sadaguia we found mismanagement of water. This calls to improve innovation efforts in order to generate economies of quantities consumed. Thus, to support the 
human and economic development and preserve ecosystems, more efficient management of water resources based on new methods are needed.

\section{REFERENCES}

[1] D. Arnaud, La technologie au cœur du développement durable : mythe ou réalité ? (Université Blaise Pascal, CERDI ClermontFerrand ; TRIANGLE, Lyon, 2001).

[2] M. Moumen, Utilisation rationnelle des eaux d'irrigation : reconversion de l'aspersion en localisée dans le Lukkos, (2003), Revue H.T.E, $n^{\circ} 125$.

[3] Patris C. et al, L'innovation technologique au service du développement durable, Centre de recherche Travail \& Technologies, Fondation Travail-Université, Namur, 2001).

[4] R. Al Atiri, T. Braham, A. Mnajja, 2003. Decentralization and Participatory Irrigation Management in Tunisia. Water Demand Management Forum on Decentralization and Participatory Irrigation Management, (2003), 2-4 February 2003, Cairo, Egypt.

[5] Z. Al Atiri, Alimentation en Eau potable des zones rurales : impact des programmes d'AEP (alimentation en eau potable) et de PPI (périmètre public irrigué) sur la vie des femmes en Milieu rural en Tunisie, (2008), colloque AQUASTRESS.ToT course, Tunisia, may 2008.

[6] CAWTAR, Regional Conference on Water Governance Sharing experiences between OECD and Arab Countries, (2009), Tunis, 89 July 2009.

[7] A. Slama A. IFAD, Experience in Participatory Irrigation Management in the NENA Region, Forum on Decentralization and Participatory Irrigation Management, Cairo, (2003), Egypt 2-4 February 2003.

[8] Stratégie de Mobilisation et de Développement des Ressources en Eau en Tunisie (1990-2000). http://www.semide.tn/contstrategie.htm

[9] S. Treyer, La Planification Stratégique à long terme de l'eau en Tunisie, (2001), Revue Tiers Monde, n 166, Avril-Juin 2001. 455474.

[10] UNDP (United Nations Development Program), Dialogue on Effective Water Governance, (2002), Update.

[11] D. Smeal, K. Lombard, M. West, M. O’Neill, R. N. Arnold, Low-Pressure Drip Irrigation for Small Plots and Urban Landscapes, Research Report , n773.

[12] D. M. Granberry, K. A. Harrison, W. T. Kelley, Drip Chemigation-Injecting Fertilizer, Acid and Chlorine, Cooperative Extension Service, (1996), University of Georgia, Bulletin $n^{\circ} 1130$.

[13] W. J. Jr. Lamont, J. K. Harper, A. R. Jarrett, M. D. Orzolek, R. M. Crassweller, K. Demchak, G. L. Greaser, Irrigation for fruit and vegetable production, Agricultural Alternatives series. University Park, PA: Penn State Cooperative Extension, (2001).

[14] H. Hammar, A. Marangoni , P. Nikhade, Modern irrigation systems improve water efficiency and generate wealth for the farming communities, (2012), World Water Week Stockholm, August 28th 2012.

[15] Ministère de l'Environnement et du Développement Durable de la République Tunisienne http://www.onagri.nat.tn

[16] N. Soussi, Les indicateurs de l'environnement et du développement durable et l'utilisation des systèmes d'information géographique, OTEDD (Observatoire Tunisien de l'Environnement et du Développement Durable, (2009).

[17] A. Mtimet, Développement durable et gestion des ressources naturelles en Tunisie, Direction des Sols, 159-162.

[18] Direction Générale du Développement Durable: Stratégie nationale de développement durable 2012-2016, Document 5/5, Consultation nationale, (2011).

[19] Ministère de l'agriculture, de l'agroalimentaire et de la forêt de la République Française, Sécheresse et agriculture : Réduire la vulnérabilité de l'agriculture à un risque accru de manque d'eau, Expertise scientifique collective, Synthèse du rapport d'expertise réalisé par l'INRA, (2006).

[20] OCDE, De l'eau pour tous : perspectives de l'OCDE sur la tarification et le financement, Paris, (2009).

[21] OCDE, La performance environnementale de l'agriculture dans les pays de l'OCDE depuis 1990, Paris, (2008).

[22] OCDE, Water and Agriculture: Sustainability, Markets and Policies, Paris, (2006).

[23] OCDE, Agriculture, sécurité alimentaire et eau: En marche vers une révolution bleue, Jacques Diouf, L'Observateur de l'OCDE, (2003).

[24] FAO (Food and Agriculture Organisation), L'irrigation avec des eaux usées traitées, manuel d'utilisation, (2003).

[25] ILRI (Institut International pour l'Amélioration et la Mise en Valeur des Terres), Gestion des eaux en irrigation : Méthodes d'irrigation, Manuel de formation $n^{\circ} 5$, préparé par C. Brouwer, (1990).

[26] UNESCO (Organisation des Nations Unies pour l'Éducation, la Science et la Culture), Programme Mondial pour l'Évaluation des Ressources en Eau (WWAP) hébergé et dirigé par l'UNESCO : www.unesco.org/new/fr/naturalsciences/environment/water/wwap/

[27] Guide technique de l'utilisation des ressources en eau : Pour une exploitation ingénieuse de ressources en eau limitées, Documentation technique de la JGRC Générer l'abondance dans le Sahel par la lutte contre la désertification, Société Japonaise des Ressources Vertes, vol. 4, (2003).

[28] L. Stravato et A. Ganaba, Application et adaptabilité des technologies de la micro irrigation développées par iDE aux contextes climatiques et pratiques burkinabés, Laurent Stravato et Aida Ganaba, (2011), www.fondationensemble.org

[29] Bulletin Mensuel d'Information et de Liaison du PNTT, Matériel d'irrigation : choix, utilisation et entretien, MARFE/ DERD, $\mathrm{N}^{\circ} 81,(2001)$.

[30] Une gestion de l'eau durable, la diffusion des technologies et connaissances, l'accès aux ressources en eau et l'encouragement à l'innovation sont les clés d'une sécurité mondiale en eau, CropLife International, Meeting Challenges in Growing World, www.croplife.org 